\title{
Using a commercially available DNA extraction kit to obtain high quality human genomic DNA suitable for PCR and genotyping from I I-year-old saliva saturated cotton spit wads
}

\author{
Erik A Ehli1 ${ }^{1}$, Timea Lengyel-Nelson ${ }^{1}$, James J Hudziak ${ }^{2}$ and \\ Gareth E Davies*1,3,4
}

\begin{abstract}
Address: ${ }^{1}$ Avera Institute for Human Behavioral Genetics, Avera Behavioral Health Center, Sioux Falls, SD, USA, ${ }^{2}$ University of Vermont, College of Medicine, Burlington, VT, USA, ${ }^{3}$ South Dakota State University, College of Pharmacy, Brookings, SD, USA and ${ }^{4}$ University of South Dakota, Sanford School of Medicine, Department of Psychiatry, Sioux Falls, SD, USA
\end{abstract}

Email: Erik A Ehli - Erik.Ehli@mckennan.org; Timea Lengyel-Nelson - Timea.Nelson@mckennan.org; James J Hudziak - James.Hudziak@uvm.edu; Gareth E Davies* - gareth.davies@sdstate.edu

* Corresponding author

Published: 22 December 2008

BMC Research Notes 2008, I:133 doi:10.1 186/1756-0500-I-133
Received: 17 November 2008

Accepted: 22 December 2008

This article is available from: http://www.biomedcentral.com/1756-0500/1/133

(C) 2008 Davies et al; licensee BioMed Central Ltd.

This is an Open Access article distributed under the terms of the Creative Commons Attribution License (http://creativecommons.org/licenses/by/2.0), which permits unrestricted use, distribution, and reproduction in any medium, provided the original work is properly cited.

\begin{abstract}
Background: We sought to describe the integrity of human genomic DNA extracted from saliva saturated cotton spit wads stored at $-20^{\circ} \mathrm{C}$ for approximately II years. 783 spit wad samples were collected from an ADHD sample population (Vermont Family Study) during 1996-2000. Human genomic DNA was extracted from the spit wads using a commercially available kit; QIAamp DNA Blood Midi Kit (Qiagen, Inc., Valencia, CA.) with a few modifications.

Results: The resulting DNA yield was more than adequate for genetic analysis and ranged from approximately I $\mu \mathrm{g}$ to a total of $80 \mu \mathrm{g}$ (mean $17.3 \mu \mathrm{gs} \pm$ II.9 $\mu \mathrm{gs}$ ). $\mathrm{A}_{260} / \mathrm{A}_{280}$ ratios for the human genomic DNA extracted from the spit wads was consistently within the generally acceptable values of I.7-2.0, with the lowest purity being I.70, and a mean value of $1.937 \pm 0.226$ for the 783 samples. The DNA also was suitable for PCR reactions as evidenced by the amplification of the serotonintransporter-linked polymorphic region, 5HTTLPR. 5HTTLPR is a functional polymorphism in the promoter region of the serotonin transporter gene (HTT, SLC6A4, or SERT), consisting of two intensively studied alleles. 770 of the 783 samples (98.3\%) produced fragments after PCR of the expected size with primers specific for 5 HTTLPR.

Conclusion: High quality and abundant genomic DNA can be successfully retrieved from saliva saturated cotton spit wads using the commercially available kit, QIAamp DNA Blood Midi Kit from Qiagen, Inc. Furthermore, the DNA can be extracted in less than 3 hours and multiple samples can be processed simultaneously thus reducing processing time.
\end{abstract}

\section{Background}

Given the increasing emphasis the study of molecular genetic influences on the development of psychiatric disorders; simple, noninvasive and cost-effective methods of collecting DNA for large-scale studies are needed for real time and remote (after years of storage) genetic analyses. Whole blood, serum, and plasma have long been the gold standard for obtaining high quality, abundant genomic 
DNA suitable for genetics studies; however, research has shown that a blood draw may be a significant barrier for study participation, especially those studies involving pediatric patients [1] with complex psychiatric disorders such as attention deficit hyperactivity disorder (ADHD) and autism spectrum illness. Buccal cells have proven to be an effective painless procedure as a means to DNA collection from large sample populations [2]. In addition, the procedure is relatively quick, cost effective, and a noninvasive means to collect genomic DNA. Buccal cells can be collected using a variety of different methods including cytobrushes, clean sterile swabs, mouthwash, saliva alone, and in the case of the Vermont Family Study with spit wads.

Genetic analysis experiments require the genomic DNA from the study sample to be of adequate quantity and quality. The affymetrix 6.0 chips, which enable genotyping of up to 1.8 million genetic markers, requires $500 \mathrm{ng}$ of total genomic DNA [3]. In addition, PCR reactions required to amplify microsatellite markers in candidate gene and linkage studies typically require $50 \mathrm{ng}$ or more of genomic DNA per marker $[4,5]$. The quality of genomic DNA extracted for experiments are typically measured using spectrophotometric absorbance ratios of $260 \mathrm{~nm} /$ $280 \mathrm{~nm}$. High quality DNA is considered to have an $\mathrm{A}_{260} /$ $\mathrm{A}_{280}$ ratio of 1.7-2.0. The quality of genomic DNA can also be measured using PCR success [6].

We sought to describe the integrity of DNA from saliva saturated cotton spit wads collected from 1996-2000 as part of an ADHD sample population known as the Vermont Family Study. The spit wads were stored at $-20^{\circ} \mathrm{C}$ for 11 years and revisited at the present time to undergo various genetic experiments, including genotyping known candidate genes, whole genome association/methylation studies, and copy number variation experiments. The information from this study may be useful to anyone who has collected buccal cells for DNA isolation using a nonconventional method.

\section{Results \\ DNA Yield}

The quantity of genomic DNA extracted from the saliva saturated cotton spit wads was determined using the conventional method of absorbance at $260 \mathrm{~nm}\left(\mathrm{~A}_{260}\right)$. We found the DNA yield from the 783 DNA extractions to be highly variable from sample to sample, with an average yield of $17.3 \mu \mathrm{gs}$ with a standard deviation of $\pm 11.9 \mu \mathrm{gs}$. Genomic DNA yield ranged from $1 \mu \mathrm{g}$ to as high as $80 \mu \mathrm{gs}$. By our own empirical observation, DNA yield seem to correlate with the saturation level of the spit wad. Spit wads heavily saturated with saliva generally produced a higher genomic DNA yield in comparison with drier spit wads.

\section{DNA Quality}

The quality of DNA was assessed using two different methods. Initially, DNA quality was determined using an $\mathrm{A}_{260} / \mathrm{A}_{280}$ ratio. Additionally, because the main purpose for collecting the DNA was for future genotyping studies, we assessed DNA quality using PCR amplification of the 5HTTLPR polymorphism. The generally used convention of assessing DNA quality with an $\mathrm{A}_{260} / \mathrm{A}_{280}$ ratio is that pure genomic DNA will have a ratio between 1.7 and 2.0. The mean $A_{260} / A_{280}$ ratio for the 783 samples was determined to be $1.937 \pm 0.226$. Interestingly, samples concentrated using Microcon YM-100 centrifugal filter devices generally increased in purity as measured using the $A_{260} /$ $\mathrm{A}_{280}$ ratio. As a result, the adjusted mean $\mathrm{A}_{260} / \mathrm{A}_{280}$ ratio of the sample population after concentrating samples that fell below our selected $50 \mathrm{ng} / \mathrm{ul}$ cutoff was $1.965 \pm 0.124$.

Using PCR analysis of the 5HTTLPR polymorphism we identified that 770 DNA samples $(98.3 \%)$ were successfully amplified and detected utilizing fragment analysis on the ABI 3130 Genetic Analyzer. 48 DNA samples were randomly selected and PCR was repeated under the same conditions and fragments were identified as concordant using gel electrophoresis. A representative gel is shown in figure 1.

\section{Discussion}

This methodology report describes the effectiveness of a commercially available kit in extracting and purifying human genomic DNA from saliva saturated cotton spit wads. We found that DNA obtained from the spit wads was of adequate quantity and quality for use in downstream genetic studies.

The yield of genomic DNA from buccal cells from spit wads was highly variable, with yields ranging from $1 \mu \mathrm{g}$ to as high as $80 \mu \mathrm{gs}$. The variability observed with DNA yield is consistent with results from other studies using buccal cytobrushes in which yields are reported from $0.5 \mu \mathrm{gs}$ to $12.66 \mu \mathrm{gs}[8,9,6,10]$. In our sample of 783 individuals, we generated a mean of $17.3 \mu \mathrm{gs} \pm 11.9 \mu \mathrm{gs}$ of genomic DNA from the spit wads. The yield of genomic DNA achieved from the spit wads would be more than adequate for numerous genetics studies including microsatellite analysis, whole genome association studies, linkage analysis, copy number variation experiments, etc.

We also report an estimate of DNA quality extracted from the Vermont Family Study samples using an $A_{260} / A_{280}$ ratio to identify DNA purity and protein contamination. DNA is generally considered to be of adequate quality when the $A_{260} / A_{280}$ ratio is between 1.70 and 2.0. The quality of genomic DNA from the saliva saturated cotton spit wads, assessed using spectrophotometer readings, was more than adequate as the mean $A_{260} / A_{280}$ ratio for 


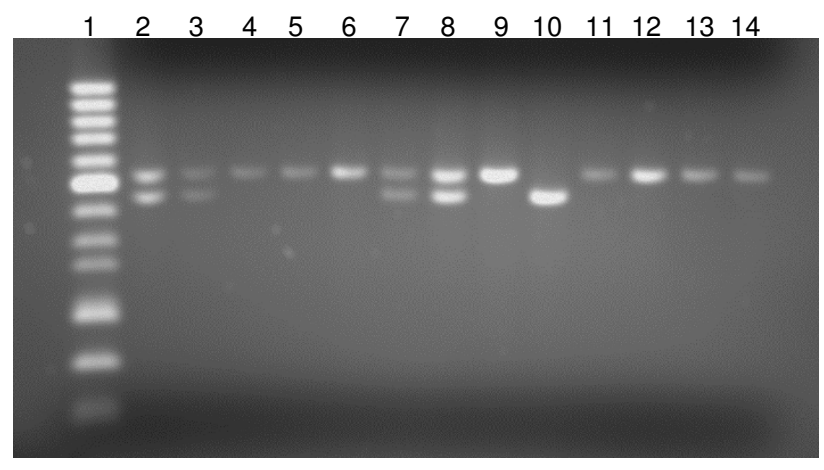

\section{Figure I}

Representative agarose gel of 5HTTLPR PCR fragments from Genomic DNA. Representative 2\% agarose gel showing fragments obtained from a PCR using genomic DNA isolated from Vermont Family Study spit wads and primers specific for 5 HTTLPR polymorphism. Lane I contains 50 bp DNA ladder (Fisher Bioreagents), with a bold reference band of $400 \mathrm{bp}$. Lane 2 is a positive control sample with known S/L genotype. Lanes 3-14 show fragments generated from 12 samples using genomic DNA extracted from spit wads as template for 5HTTLPR PCR reaction. $12.5 \mu \mathrm{l}$ of the $25 \mu \mathrm{lPCR}$ reaction was mixed with $2 \mathrm{ul}$ of $6 \mathrm{X}$ agarose DNA loading dye (Fisher Bioreagents) prior to loading the gel.

the 783 samples was $1.937 \pm 0.226$. Since the DNA was to be banked for future genetic studies, we imposed a $50 \mathrm{ng} /$ $\mu \mathrm{l}$ concentration cut-off for each sample prior to being stored at $-20^{\circ} \mathrm{C}$. Samples with concentrations below this threshold were concentrated using Microcon YM-100 centrifugal filter units. Interestingly, after concentrating these samples through the filter unit, the purity as measured by an $A_{260} / A_{280}$ ratio increased. The adjusted mean after concentration of samples falling below the $50 \mathrm{ng} / \mu \mathrm{l}$ cutoff was $1.965 \pm 0.124$. Most likely, any contaminants or impurities are removed during the concentration procedure increasing purity of the genomic DNA prep.

In addition, the quality of genomic DNA was also assessed by PCR success using primers specific for the 5HTTLPR polymorphism. We identified a $98.3 \%$ success rate $(770 /$ 783) with the genomic DNA as a template for this PCR reaction. A representative gel is shown in figure 1 showing the fragments observed from a PCR reaction with 5HTTLPR specific primers.

\section{Conclusion}

This report describes a novel, cost effective, and efficient way to collect genomic DNA from individuals enrolling in genetic studies. This method should enable researchers to obtain high quality and abundant genomic DNA that can be successfully retrieved from saliva saturated cotton spit wads using the commercially available kit, QIAamp DNA Blood Midi Kit from Qiagen, Inc. Furthermore, the DNA can be extracted in less than 3 hours and multiple samples can be processed simultaneously thus reducing processing time and cost.

\section{Methods \\ Participants}

The Vermont Family Study is a collection of samples from 207 families comprising 783 individuals. 167 families were part of an ADHD sample with one member of each family recognized as a Proband for the disorder. 40 families were included as control families with no DSM-IV diagnoses.

\section{Sample Collection}

Participants were asked to refrain from eating or drinking 1 hour prior to saliva collection. Each individual was instructed to place a standard 2" $\times 2$ " piece of cotton gauze in the buccal region of their cheek for 3 minutes. The saliva saturated cotton spit wad was removed, rolled to fit a collection tube, and stored at $-20^{\circ} \mathrm{C}$ until the genomic DNA was extracted. All data collected and analyzed with approval of the UVM COM IRB Ethics Committee.

\section{DNA Extraction and Quantification}

All DNA extractions were performed at the Avera Institute for Human Behavioral Genetics. DNA was extracted from saliva saturated cotton spit wads using a column-based purification method. Rolled spit wads measured approximately, $5 \mathrm{~cm} \times 1.5 \mathrm{~cm}$, and DNA was extracted from buccal cells using the QIAamp DNA Blood Midi Kit large volume protocol (Qiagen) according to the manufacturer's instructions with a few modifications. The spit wad was incubated at $70^{\circ} \mathrm{C}$ in a Protease/Lysis buffer mixture (200 ul Qiagen Protease/2.4 ml buffer AL) for 30 minutes in a $15 \mathrm{ml}$ conical tube (Fisher Scientific). The lysate was separated from the spit wad using centrifugal force by placing the spit wad in the barrel of a $5 \mathrm{ml}$ syringe (Becton Dickson) that was seated in a conical $15 \mathrm{ml}$ tube and centrifuged for 10 minutes at $12,000 \mathrm{rpm}$. The spit wad was discarded and $2 \mathrm{ml}$ absolute ethanol was added to the lysate and the tube was mixed by vigorous shaking (vortexing). Approximately one half of the lysate/ethanol mixture was transferred to a Qiagen Midi column placed in a clean $15 \mathrm{ml}$ conical tube. The column was centrifuged @ $1850 \times \mathrm{g}$ for 3 minutes. The filtrate was discarded and the remaining lysate/ethanol mixture was applied to the same column and centrifuged @ $1850 \times \mathrm{g}$ for 3 minutes. The column was washed with 2 mls of buffer AW1 and centrifuged @ $3220 \times \mathrm{g}$ for 2 minutes. The column was washed a second time with $2 \mathrm{mls}$ of buffer AW2 and centrifuged @ $3220 \times \mathrm{g}$ for 30 minutes to ensure complete drying. DNA was eluted from the column into a clean $15 \mathrm{ml}$ conical tube by adding $200 \mu \mathrm{l}$ buffer AE to the column, incu- 
bating at room temperature for 5 minutes, and centrifuging@3220×g for 4 minutes. For maximum DNA yield a second elution was performed as described above, yielding approximately $400 \mu \mathrm{l}$ total volume. DNA concentration and purity were determined using UV spectrophotometry (Nanodrop). All genomic DNA was either diluted or concentrated to a final concentration of $50 \mathrm{ng} /$ ul. DNA was diluted in a reduced EDTA buffer $(10 \mathrm{mM}$ Tris-HCL, $0.1 \mathrm{mM}$ EDTA, pH 8.0) and concentrated using Microcon YM-100 centrifugal filter devices (Millipore) according to the manufacturer's instructions.

\section{PCR Amplification}

The Quality of DNA isolated from the spit wad was assessed by PCR amplification of the serotonin-transporter-linked polymorphic region (5HTTLPR). PCR products were visualized using $2 \%$ agarose gel electrophoresis or fragment analysis on an ABI 3130 Genetic Analyzer (Applied Biosystems, Inc.). Primer sequences for 5HTTLPR were previously described; forward primer $\left(5^{\prime}\right.$ ATGCCAGCACCTAACCCCTAATGT-3') and the reverse primer (5'- GGACCGCAAGGTGGGCGGGA-3') [7]. When running samples on the 3130 genetic analyzer a fluorescently tagged forward primer (6FAM, Applied Biosystems) was used to tag the PCR product for fragment analysis. This primer pair amplifies a 419 base pair product for the 16-repeat long (L) allele and a 375 base pair product for the 14-repeat short (S) allele. PCR reactions were performed using a PCR Master Mix (Promega) containing a final concentration of $1.5 \mathrm{mM} \mathrm{MgCl} 2,1 \times$ reaction buffer, $200 \mu \mathrm{M}$ of each dNTP, $40 \mathrm{ng}$ purified genomic DNA, 1.25 units Taq DNA polymerase, and 5 pmols of each primer in a $25 \mathrm{ul}$ reaction. PCR cycling conditions consisted of an initial denaturation at $95^{\circ} \mathrm{C}$ for 15 minutes, 35 cycles each consisting of $30 \mathrm{~s}$ at $94^{\circ} \mathrm{C}, 30 \mathrm{~s}$ at $66^{\circ} \mathrm{C}$, and $40 \mathrm{~s}$ at $72^{\circ} \mathrm{C}$. Elongation was continued for $15 \mathrm{~min}$ at $72^{\circ} \mathrm{C}$ after the last cycle. S vs. L fragments were called using GeneMapper Software Version 4.0 (ABI), or fragments were separated on a $2 \%$ agarose gel supplemented with ethidium bromide $(0.02 \%$, Fisher).

\section{Competing interests}

The authors declare that they have no competing interests.

\section{Authors' contributions}

EAE: Participated in design of study, manuscript preparation, DNA extraction, and PCR analysis, TLN: Participated in DNA extraction and PCR analysis, JJH: Designed and executed collection of spit wads in Vermont Family Study and manuscript preparation, GED: Participated in design of study and manuscript preparation

\section{Acknowledgements}

This study was funded by Avera McKennan Hospital and University Health Center through a partnership with South Dakota State University and the University of South Dakota.

\section{References}

I. Dlugos DJ, et al.: Recruitment rates and fear of phlebotomy in pediatric patients in a genetic study of epilepsy. Epilepsy Behav 2005, 6(3):444-6.

2. Calle EE, et al.: The American Cancer Society Cancer Prevention Study II Nutrition Cohort: rationale, study design, and baseline characteristics. Cancer 2002, 94(9):2490-50।.

3. Affymetrix: Data Sheet: Affymetrix ${ }^{\circledR}$ Genome-Wide Human SNP Array 6.0. [http://www.affymetrix.com/support/technical/ datasheets/genomewide snp6 datasheet.pdf].

4. Buerger $\mathrm{H}$, et al.: Genetic characterisation of invasive breast cancer: a comparison of CGH and PCR based multiplex microsatellite analysis. J Clin Pathol 200I, 54(I I):836-40.

5. Hoque MO, et al.: Genome-wide genetic characterization of bladder cancer: a comparison of high-density single-nucleotide polymorphism arrays and PCR-based microsatellite analysis. Cancer Res 2003, 63(9):2216-22.

6. King IB, et al.: Buccal cell DNA yield, quality, and collection costs: comparison of methods for large-scale studies. Cancer Epidemiol Biomarkers Prev 2002, I I ( 10 Pt I): I I30-3.

7. Gelernter J, Kranzler H, Cubells JF: Serotonin transporter protein (SLC6A4) allele and haplotype frequencies and linkage disequilibria in African- and European-American and Japanese populations and in alcohol-dependent subjects. Hum Genet 1997, 101(2):243-6.

8. Rogers NL, et al: New saliva DNA collection method compared to buccal cell collection techniques for epidemiological studies. Am J Hum Biol 2007, 19(3):319-26.

9. Garcia-Closas M, et al: Collection of genomic DNA from adults in epidemiological studies by buccal cytobrush and mouthwash. Cancer Epidemiol Biomarkers Prev 2001, 10(6):687-96.

10. Neuhaus T, et al.: Reliability of non-invasively acquired human genomic DNA as a substrate for real-time PCR-assisted analysis of genetic polymorphisms. Arch Toxicol 2004, 78(7):390-6.

\begin{tabular}{|l|}
\hline Publish with Biomed Central and every \\
scientist can read your work free of charge \\
"BioMed Central will be the most significant development for \\
disseminating the results of biomedical research in our lifetime. " \\
Sir Paul Nurse, Cancer Research UK \\
Your research papers will be: \\
• available free of charge to the entire biomedical community \\
• peer reviewed and published immediately upon acceptance \\
• cited in PubMed and archived on PubMed Central \\
• yours - you keep the copyright \\
Submit your manuscript here: \\
http://www.biomedcentral.com/info/publishing_adv.asp
\end{tabular}

